\title{
PODER JUDICIAL, JUSTICIA INCLUSIVA Y JUSTICIA INTERCULTURAL
}

\author{
Dedicado al Doctor Fernando Silva Santisteban
}

VÍCTOR MALPARTIDA CASTILLO*

\begin{abstract}
Resumen
Se tiene como aspecto central el recuento de cómo el Poder Judicial ha ido asumiendo la justicia intercultural, desde la valoración del peritaje antropológico hasta la realización de congresos internacionales de justicia intercultural, preocupándose constantemente por la relación entre la justicia denominada ordinaria y la justicia comunal, planteándose finalmente un Proyecto de Ley de Coordinación y Armonización Intercultural de la Justicia en 2011.
\end{abstract}

Palabras clave: Antropología jurídica - Interculturalidad - Poder Judicial Administración de justicia - Justicia intercultural - Justicia inclusiva.

\begin{abstract}
The central aspect here is an account of how the Judiciary has gradually assumed an intercultural form of justice, ranging from the valuation of the anthropological appraisal to the organization of international congresses of intercultural justice, with constant concern for the relationship between ordinary justice and communal justice, ending with an Intercultural Coordination and Harmonization of Justice Bill in 2011.
\end{abstract}

Key words: Legal Anthropology - Interculturality - The Judiciary Administration of Justice - Intercultural Justice - Inclusive Justice.

\section{Sumario}

1.- Introducción. 2.- Un factor clave: desarrollo de la antropología jurídica. 3.- Administración de justicia: hacia una justicia intercultural. 3.1.- Acerca del peritaje antropológico. 3.2.- Propuesta de Juzgado de Paz No Letrado Especializado en Asuntos Indígenas. 3.3.- Primera Escuela de Justicia Intercultural. 3.4.- Acuerdo Plenario sobre las Rondas Campesinas y el Derecho Penal. 3.5.- Proyecto de ley de Coordinación y Armonización Intercultural de la Justicia. 3.6.- Congresos Internacionales de Justicia Intercultural. 4.-Pluriculturalidad, multiculturalidad e interculturalidad. 5.- Base jurídica de la justicia intercultural. 6.- A manera de conclusión: interculturalidad como proceso inclusivo y como meta.

* Juez Superior Titular de la Corte Superior de Justicia de Ica - Poder Judicial del Perú. 


\section{INTRODUCCIÓN}

Hace unos años atrás, se opinaba en relación al discurso judicial habido en la jurisprudencia, señalando que en dicho discurso "se expresa con mayor nitidez, a veces caricaturesca, lo que la simple lectura de la ley sólo puede mostrar muy discretamente: los prejuicios etnocentristas, la negación de valores a la población indígena, la identificación entre mercado capitalista y civilización occidental, el profundo desprecio por quienes son "indios"; en suma, el carácter marcadamente étnico de la dominación social en el Perú". Se completaba lo dicho así: "De esta manera, aparece demostrado cómo este Estado, que se afirma mediante un derecho de pretensión universalizadora, no sólo niega las clases sociales sino que viola la diversidad étnico - cultural" ${ }^{1}$.

El derecho y la administración de justicia, desde ésta perspectiva, negaban lo evidente en la sociedad peruana: la pluralidad cultural, resaltándose la violentación de la misma. Y esto solo era parte del comportamiento de un Estado como el peruano ${ }^{2}$.

Enla actualidad, existe un panorama algo distinto aunque aún en construcción ${ }^{3}$. En la sensibilización y concientización de un país pluricultural, multiétnico y multilingüe, de una diversidad envidiable, en suma de un país como el que representó José María ARGUEDAS cuando señalaba que en el Perú se encuentran "todas las naturalezas del mundo en su territorio, casi todas las

\footnotetext{
1 Pásara, Luís: Presentación a: «Etnia y Represión Penal». Francisco BALlón AgUiRRE. Edición CIPA, Lima, 1980, p. 10.

2 NÚNÉE PALOMINO respecto a la legalización de las comunidades campesinas señala: "El proceso de legalización es un campo fecundo e importante para analizar las cambiantes y diversas actitudes mantenidas por el Estado hacia las comunidades campesinas. Un ejemplo de esto son aquellas leyes que han tratado de definir oficialmente lo que es una "comunidad campesina", mostrando cómo son percibidas estas instituciones por los legisladores. Usualmente, estas leyes también contienen un modelo de organización comunal, los requisitos para obtener reconocimiento del Estado, los derechos y obligaciones de los comuneros, la forma de tenencia de la tierra, la oficina o entidad estatal encargada de estos asuntos. El análisis de todos estos aspectos en una ley determinada nos brinda la oportunidad de descubrir qué tipo de política busca desarrollar el Estado ante las comunidades campesinas. Así, este puede estar más o menos interesado en reconocer a las comunidades, aumentando o disminuyendo -por ejemplo- los requisitos y pasos para lograrlo. O puede también desear reconocer e incrementar la autonomía comunal, permitiendo o promoviendo así un "pluralismo jurídico débil"" (NúÑez PALOMINO, Pedro Germán. "Derecho y Comunidades Campesinas en el Perú 1969-1988». Centro de Estudios Regionales Andinos "Bartolomé de las Casas". Cusco, mayo 1996, p. 11).

3 AtARAma expresa lo siguiente: "La Justicia Comunal Indígena en la Región Loreto o como lo llama la Constitución, la Jurisdicción Especial, no ha sido debidamente investigada, pues, pese a estar debidamente reconocida por la Constitución de 1993, en el artículo $149^{\circ}$, es decir a pesar de haber transcurrido diecinueve años desde la vigencia de la Constitución, sin embargo no se conoce cuáles son sus características, cómo funciona, quién la administra, cuáles son sus límites y cómo se relaciona con la justicia Ordinaria, y sobre todo cómo debería ser respetada por la Justicia oficial." (ATARAMA LONZOY, Aldo Nervo. «Justicia Comunal Indígena». Corte Superior de Justicia de Loreto, Iquitos, junio 2012, p.2).
} 
clases de hombres" "4 un país de "todas las sangres", han contribuido diversos factores y presenta un desarrollo del pensamiento social.

\section{UN FACTOR CLAVE: DESARROLLO DE LA ANTROPOLOGÍA JURÍDICA}

Desde la Antropología Jurídica, un hito incuestionable en el desarrollo enunciado es precisamente lo ocurrido a partir de la década del cincuenta. Señala Deborah POOLE ${ }^{5}$-a quien seguimos en esta parte- que al inyectar una dosis de historia en el estudio antropológico de las sociedades andinas y posteriormente amazónicas, algunos autores abrieron algunas pistas para la antropología jurídica y crearon las condiciones que más tarde harían posible imaginar un "pluralismo legal".

Dentro de estos autores, figura descollante es la de José María ARGUEDAS, quien en el trabajo titulado Las comunidades de España y el Perú rompió con el esquema etnohistórico tradicional, al preguntarse cuáles eran las raíces españolas y por lo tanto, coloniales de la comunidad indígena peruana. ARGUEDAS resaltaba que en las comunidades rurales españolas estudiadas por él, la vecindad y propiedad territorial son conceptos idénticos; sin embargo, al trasladarse esta categoría jurídica española al contexto colonial sufre una evidente transformación. Cuando los españoles asumen la condición de colonizadores y, aplicando sus modelos de comunidad a la organización de la población nativa americana, dejan de reconocer los estatus de vecindad y comuna como derechos complementarios, dándoles una atribución étnica o racial. Esta observación de ARGUEDAS, señala Deborah POOLE, sugiere que la integridad de la sociedad indígena no parte de un patrón cultural indígena o una mera supervivencia, sino de la interacción dinámica entre las formas de organización social propias de los Andes y el derecho consuetudinario español ${ }^{6}$.

4 ARguedas, José María. «Obras Completas». Tomo V. Editorial Horizonte, Lima 1983, p. 198.

5 Poole, Déborah: "La ley y la posibilidad de la diferencia: la antropología jurídica peruana entre la justicia y la ley". En: Degregori, Carlos Iván; SENDÓn, Pablo y Pablo SANDOVAl (Editores). «No hay país más diverso». Compendio de Antropología Peruana II. Instituto de Estudios Peruanos. Lima 2012, pp. 212 y 213.

6 En sus propias palabras Arguedas explica lo anterior: “a) Los colonizadores españoles disfrutaban ya de una experiencia propia y muy antigua del aprovechamiento comunal de la tierra, mediante la adjudicación de parcelas de arar a cada miembro de una comunidad y de usufructo común de los pastos. La aplicación por los españoles de su propia experiencia a un gran imperio donde encontraron sistemas de explotación de la tierra tan semejantes al suyo constituyó una tarea relativamente fácil y evidentemente necesaria y lógica. Más fácil que la relativamente equivalente que aplicaron durante el proceso de la reconquista, en la propia península. b) La Corona tuvo en cuenta sus intereses específicos, que no concordaron siempre con los intereses de los colonizadores y, al trazar la política relativa a la administración de las comunidades de indios, trataron de protegerlas de la voracidad de los vecinos españoles, otorgándoles ciertas garantías que impidieran el enriquecimiento ilimitado de los colonos. Frenar la capitalización de los colonos, la formación 
Lo anterior, entonces, abrió, como señala la autora citada, por lo menos dos caminos para la antropología jurídica: el estudio de los usos de la ley para el despojo y la explotación del indígena en los tribunales coloniales y el estudio de las raíces jurídicas de la cultura reivindicativa propia a las comunidades y organizaciones indígenas ${ }^{7}$.

Como indicativo del paso hacia un pluralismo legal, advierte Deborah Poole que existe una lógica que guiaba la antropología jurídica en el Perú. Así, si "la ley" era monopolio del Estado, entonces las formas de reconciliación y arbitraje con que las disputas se resuelven en las sociedades no-estatales eran relegadas a la categoría de la "costumbre". Lo importante de este esquema para la formación de una antropología jurídica del pluralismo -concluye la autora- es que "la costumbre" siempre se imagina como una forma de control social, propia de las culturas tradicionales y "orales" que no sólo existen fuera del Estado -con sus cortes, códigos y legisladores- sino en oposición a él ${ }^{8}$.

\section{ADMINISTRACIÓN DE JUSTICIA: HACIA UNA JUSTICIA INTERCULTURAL}

El inocultable cambio que conlleva lo anterior, tiene como acompañamiento un nuevo sentir en lo que respecta a la administración de justicia, distinto al que analizaba y criticaba PÁSARA. Es aún tímido pero saludablemente diferente.

Así, en los últimos años la judicatura ha volcado su interés en lo que se denomina justicia intercultural, como corolario de una serie de aspectos importantes que han ido presentándose como pasos previos a lo que

\footnotetext{
de una burguesía fuerte y de una clase de terratenientes propietarios perpetuos de la tierra fue uno de los objetivos de la política real, porque de este modo se impedía las posibilidades de independización de colonos que habitaban un continente tan lejano y tan pleno de medios de producción. Para este fin, la Corona conservó la propiedad legal de las tierras y la propiedad de los indios, permitiendo que los vecinos disfrutaran de ambos instrumentos de enriquecimiento, pero supeditándolos a la autoridad y a los intereses particulares del rey. Esta política y los métodos que se emplearon para aplicarla hicieron que los pueblos de indios, después de las reducciones que Toledo aplicó implacablemente, disfrutaron de un Término Comunal, de una propiedad común de tierras de arar y de pastos, los que, según Mishkin, fueron tomadas de las tierras que estaban destinadas al pueblo en el Imperio. Las palabras Común y Comunero y los conceptos que expresan se incorporan bien pronto al lenguaje general de indios y vecinos. Comunero se convirtió en sinónimo de indio, Común es sinónimo de ayllu y Comunidad. Así, un indio dice "comunmi kani" (soy común, o pertenezco al común) o "comunero kani" (soy comunero). El término vecino (sinónimo de comunero en los pueblos de Sayazo y Aliste) sirve para nombrar genéricamente a los españoles radicados en el Perú que adquieren en América la jerarquía de los "señoritos" de España. c) El comunero no tiene o no posee vecindad; porque, igualmente, esta palabra, de acuerdo con el nuevo sentido que adquiere en América, significa otra cosa que en Sayazo y Aliste (...)" (ARguedAS, José María. "Las Comunidades de España y del Perú». Universidad Nacional Mayor de San Marcos, Lima 1968, pp. 329-330).

7 POOLE, Déborah. Ob. Cit., p. 214.

8 Ibidem, p. 218.
} 
está pasando ahora. Es importante señalar así, al peritaje antropológico; igualmente, la propuesta presentada para la Creación y Funcionamiento del Primer Juzgado de Paz No Letrado Especializado en Asuntos Indígenas de Ucayali; también, la creación de la primera Escuela de Justicia Intercultural el 13 de noviembre de 2009 por acuerdo de la Sala Plena de la Corte Superior de Justicia de San Martín; asimismo, el V Pleno Jurisdiccional de las Salas Penales Permanentes y Transitorias de la Corte Suprema de Justicia de la República, en donde se arribó al Acuerdo Plenario N 1-2009/CJ-116, sobre las Rondas Campesinas y el Derecho Penal, llevado a cabo en Lima, el 13 de noviembre de 2009; también el impulso para la dación de una Ley de Justicia de Paz y, asimismo la presentación como iniciativa legislativa del Proyecto de Ley de Coordinación y Armonización Intercultural de la Justicia en 2011; y, finalmente, los cuatro Congresos Internacionales sobre Justicia Intercultural en Pueblos Indígenas, realizados en La Merced, Cajamarca, Huaraz y Lima, en 2009, 2010, 2011 y $2012^{9}$, respectivamente, impulsados originalmente por el doctor Javier Villa Stein.

\subsection{Acerca del peritaje antropológico}

Lo primero en mencionar es lo que concierne al denominado "peritaje antropológico". Francisco Ballón da cuenta que tiene conocimiento de tres informes antropológicos en la década del setenta, preparados por, en primer lugar, Stefano VARESE y, asimismo, otros dos elaborados por los religiosos Jesús Víctor SAN ROMÁN y Luís URIARTE, incluyendo dos de ellos como anexos en su libro ${ }^{10}$. No obstante lo dicho, GUEVARA GIL señala que dicha pericia fue empleada en el área penal en la Corte Superior de Justicia de Loreto a fines de los noventa, para invocar el error de comprensión culturalmente condicionado, sancionado en el artículo $15^{\circ}$ del Código Penal, y con el objetivo de obtener la exención o reducción de la pena ${ }^{11}$.

Citando al jurista colombiano Hernán Darío BeNíTEZ, Guevara GIL señala que el peritaje antropológico tiene dos objetivos específicos, a saber, dirimir si una persona pertenece a un universo social y cultural diferente al consagrado en la ley penal y si esa pertenencia lo hizo actuar ilícitamente, sin comprender el carácter delictivo que su acto tiene para el derecho oficial (o, si aún comprendiendo una norma no es capaz de motivarse por ella).

\footnotetext{
9 A la fecha de la publicación de la presente edición, se ha celebrado el V Congreso Internacional sobre Justicia Intercultural, realizado en la ciudad de Piura el 21 de diciembre del 2013.

10 BALlón, Francisco. Ob. Cit., p. 66.

11 Guevara GIL, Armando. «Diversidad y Complejidad Legal. Aproximaciones a la Antropología e Historia del Derecho». Fondo Editorial de la Pontificia Universidad Católica del Perú, Lima 2009, p. 192.
} 
Por eso -advierte-, el peritaje antropológico no es el lugar adecuado para ensayar elaboraciones teóricas y etnográficas sobre "una cultura". Es más bien -añade-, un instrumento judicial que ilustra a los magistrados sobre las características culturales específicas de la persona imputada penalmente ${ }^{12}$.

Del análisis de los mencionados peritajes antropológicos en la Corte Superior de Justicia de Loreto, GuEVARA GIL da algunas conclusiones señalando, en primer lugar, que desde el punto de vista de la utilidad casuística de los peritajes antropológicos practicados en los expedientes revisados, el balance es positivo ya que contribuyeron a formar la convicción judicial sobre la responsabilidad penal de los procesados y sustentaron la aplicación de la legislación especial (e.g., artículo 15, CP 1991) en casos específicos.

Sin embargo -aclara-, desde el punto de vista de la naturaleza, función y finalidad de la pericia como institución judicial, el balance es negativo. En la práctica -continua diciéndonos- el peritaje antropológico se halla desnaturalizado, cumple una función arbitraria y se le ha asignado una finalidad predeterminada, a saber, servir de fundamento para la aplicación del artículo 15 sobre el error culturalmente condicionado. En realidad -concluye-, el examen debería servir para ilustrar a los jueces sobre la pertenencia cultural del procesado y si ese universo simbólico y social lo condujo a actuar de manera ilícita (desde el punto de vista del derecho oficial).

Concluye diciendo: "Por eso, en términos globales el balance resulta negativo. La aplicación sesgada del peritaje y la ley penal especial contradice el sentido emancipatorio e intercultural que en teoría los fundamenta (...) ambos adquieren una función hegemónica y hasta discriminadora pues, en la práctica judicial, la diferencia cultural se define como carencia de conocimientos y fuente de incapacidad en los patrones culturales y legales de la sociedad dominante. Esta inversión del sentido original de la legislación especial impide una lectura intercultural de la conducta de los procesados indígenas y los obliga a reconocerse como incapaces (en la cultura hegemónica) para poder invocar la aplicación del artículo 15 del $\mathrm{CP}^{\prime \prime 13}$.

\subsection{Propuesta de Juzgado de Paz no Letrado especializado en asuntos indígenas}

Igualmente, es importante reseñar la propuesta presentada para la Creación y Funcionamiento del Primer Juzgado de Paz No Letrado Especializado en

\footnotetext{
12 Ibidem, p. 198.

13 Ibídem, p. 230.
} 
Asuntos Indígenas de Ucayali, por parte del Instituto Regional de Desarrollo de Comunidades Nativas (IRDECON), organismo perteneciente al Gobierno Regional de Ucayali (cuya dirección ejecutiva se encuentra a cargo de un indígena) y la ONG Instituto Indígena Paz y Desarrollo, presentada el 15 de diciembre de 2005. En dicha propuesta se señalaba: "sería la instancia de coordinación entre el Poder Judicial y la jurisdicción especial que ejercen las autoridades tradicionales de comunidades campesinas y nativas para administrar justicia en el ámbito de sus territorios comunales de acuerdo a su derecho consuetudinario, asimismo, este ente judicial definirá el límite de la jurisdicción especial y el ejercicio de su identidad étnica y cultural, estableciendo si cabe sanción como delito por vulneración de los derechos humanos producidas fuera del territorio comunal, en este caso aplicando el caso del error de comprensión culturalmente condicionado dispuesto por el artículo 15 y el artículo 45 referente cultural de los sujetos"14.

Presentada la propuesta, la Corte Superior de Justicia de Ucayali la observaría, en varios aspectos, siendo nuevamente presentada por IRDECON titulándola así: Creación de Juzgados de Paz y Oficina de Coordinación de la Jurisdicción Especial de Comunidades Nativas en la Corte Superior de Justicia de Ucayali, proponiendo esta vez la creación de 89 Juzgados de Paz, correspondientes al mismo número de comunidades nativas.

En respuesta a esta propuesta, la gerencia general del Poder Judicial señala, en primer lugar, que "es pertinente aclarar que el pedido de crear Juzgados de Paz especializados en Asuntos Indígenas, no está contemplado en el Texto Único Ordenado de la Ley Orgánica del Poder Judicial, aprobado por Decreto Supremo No 017-93-JUS y sus modificatorias". Asimismo, añade que "el Consejo Ejecutivo ha creado la Oficina Nacional de Apoyo a la Justicia de Paz-ONAJUP- cuyo reglamento está para aprobación y en el que se han previsto Oficinas Descentralizadas en cada Distrito Judicial, una de cuyas funciones será la de coordinación, por tanto no es necesario a la fecha crear la indicada Oficina, en tanto no se pronuncie el Consejo Ejecutivo".

Asimismo, la gerencia general del Poder Judicial requería la información siguiente: a) petición formal escrita de la autoridad de cada comunidad nativa correspondiente y en caso que sean varios juzgados pertenecientes a una misma etnia, debe constar el pedido expreso de la autoridad de la zona; $b$ ) completar por cada propuesta de Juzgado de Paz, los datos que se indican

${ }_{14}$ MATOS, James. «¿La interculturalidad se abre paso en las Cortes Superiores de Justicia de la Amazonía peruana?»; p. 6. 
en ficha adjunta; el caso de caseríos o anexos de una misma etnia, señalar las zonas conforme denominación en castellano y/o en el idioma nativo si es posible; c) en caso de incluir la petición para un nuevo Juzgado de Paz, en ámbito de un Juzgado de Paz creado y en actual funcionamiento, se requiere: 1. En ambos casos señalar los nuevos límites, 2. Adjuntar copia fedateada de la Resolución Administrativa de creación del Juzgado de Paz; plano o croquis de ubicación actual y precisar conforme la propuesta; d) señalar la forma precisa de cada Juzgado de Paz; e) conflictos más comunes; f) documento de entidad oficial que reconozca las comunidades nativas o etnias, preferible si hay información adicional del territorio que abarca cada una; y, g) otra información que considere pertinente ${ }^{15}$.

Lamentablemente, esta propuesta quedaría primero estancada y luego acabaría archivada, ya que completarla conllevaba un esfuerzo que excedía al de los propulsores.

\subsection{Primera Escuela de Justicia Intercultural}

Otra experiencia importante en la asimilación de la interculturalidad por parte del Poder Judicial, fue la creación de la primera Escuela de Justicia Intercultural el 13 de noviembre de 2009, por acuerdo de la Sala Plena de la Corte Superior de Justicia de San Martín, mediante la Resolución Administrativa $\mathrm{N}^{\circ}$ 408-2009-P-CSJSM/PJ, la misma que fue publicada el 26 del mismo mes de noviembre, estableciéndose en la ciudad de Moyabamba.

Se explica así la creación de la Escuela: "La Escuela de Justicia Intercultural, en adelante "La Escuela", parte de la realidad local del distrito judicial de San Martín, el cual es de una realidad "(...) heterogénea y plural en la que coexisten dinámicamente diversas culturas y etnias que tienen su particular cosmovisión, racionalidad, manera de vivir, lenguas, tradiciones, construcción del tiempo y el espacio, sistemas normativos y mecanismos que solucionan sus conflictos $(\ldots)$ ", así como de "(...) la necesidad de garantizar el derecho de toda persona a la tutela judicial efectiva y al libre acceso al sistema de impartición de justicia (...)", lo cual expresa el esfuerzo para que en el país, partiendo de una experiencia regional, se implemente las reformas de fondo que la justicia en el país espera"16.

\footnotetext{
15 Ibídem, p. 7.

16 «Escuela de Justicia Intercultural. Distrito Judicial de San Martín: Documento Guía de Desarrollo, San Martín»; marzo de 2010, p.3.
} 


\subsection{Acuerdo Plenario sobre las Rondas Campesinas y el Derecho Penal}

Por otra parte, especial atención merece el V Pleno Jurisdiccional de las Salas Penales Permanentes y Transitorias de la Corte Suprema de Justicia de la República, en donde se arribó al Acuerdo Plenario Nº 1-2009/CJ-116, sobre las Rondas Campesinas y el Derecho Penal, llevado a cabo en Lima, el 13 de noviembre de 2009.

Explicando el mencionado Acuerdo Plenario, el doctor Víctor PRADO SALDARRIAGA ${ }^{17}$ señala que en él se desarrollan dos aspectos esenciales. Por un lado, la asimilación de un innovador enfoque jurisdiccional sobre el rol y la trascendencia de las funciones de control social que ejercitan las rondas campesinas en el país. Y, por otro lado, la definición de criterios de orientación que sirvan de referencia a la judicatura nacional, para el tratamiento adecuado de los casos penales donde se ven involucradas personas que integran tales organizaciones comunales.

Precisa el juez supremo que: “En cuanto a lo primero, el Acuerdo Plenario plantea abiertamente la necesidad de entender y reconocer la presencia formal y material de la interculturalidad en el ejercicio de la administración de justicia penal en el Perú. Y en relación a lo segundo, se precisa que la jurisdicción formal debe visualizar siempre a la interculturalidad como un proceso dinámico e interactivo, basado en objetivos de cooperación mutua en igualdad de condiciones. Por tanto, su percepción no debe limitarse a la declaración de sesgados actos de reconocimiento de una manifestación estática del pluralismo jurídico, o a la existencia, siempre subordinada, de órganos jurisdiccionales comunales de segundo nivel o de operatividad limitada y subsidiaria"18 19 .

17 Prado Saldarriaga, Víctor: «El Acuerdo Plenario N 1-2009/CJ-116 de la Corte Suprema: "Rondas Campesinas y el Derecho Penal». En: Congresos Internacionales sobre justicia intercultural en pueblos indigenas, comunidades andinas y rondas campesinas. Fondo Editorial del Poder Judicial, Lima 2011, p.171.

18 Ibidem, p. 171.

19 LA ROSA precisa: “De este modo, paulatinamente se ha ido reformulando esta visión tradicional dada la necesidad de reconocer una noción más amplia del derecho al acceso a la justicia que permita incorporar dentro de su contenido las funciones jurisdiccionales de las comunidades campesinas y nativas (pueblos andinos y amazónicos), en primer lugar, pero posteriormente de otros grupos sociales o culturales que tienen características similares y que suplen la inacción estatal en la impartición de justicia. Por esas consideraciones, sostenemos que el Acuerdo Plenario comentado se encuentra dentro de aquellas disposiciones que conciben el derecho al acceso a la justicia como el derecho de todas las personas, sin distinción de sexo, raza, edad, identidad sexual, a obtener una respuesta satisfactoria a sus necesidades jurídicas, configurándose de este modo una visión integral de este derecho que en nuestro caso incorpora el ejercicio de la función jurisdiccional que las comunidades y rondas campesinas vienen haciéndolo actualmente".(LA ROSA CALLE, Javier. «Presentación en: La Facultad Jurisdiccional de las Rondas Campesinas». Instituto de Defensa Legal, Lima 2010, pp. 5-6). 
Como conclusiones del significado de este Acuerdo Plenario se pueden señalar:

1. El Acuerdo Plenario ha promovido en la judicatura nacional una reflexión integral sobre el tratamiento penal de los delitos imputados a ronderos, a partir de un innovador enfoque intercultural.

2. A partir del Acuerdo Plenario las relaciones de coordinación entre las autoridades ronderiles y de la justicia penal ordinaria serán más fluidas y equitativas, así como menos tensas.

3. El interés generado en la comunidad jurídica nacional sobre los alcances del Acuerdo Plenario, se viene expresando en diferentes espacios de opinión como foros y publicaciones, lo cual coadyuvará a su difusión y retroalimentación.

4. El Poder Judicial como muestra de su transparente compromiso con una justicia intercultural, realizó el año 2010, en la ciudad de Cajamarca, un Congreso Internacional sobre Justicia Intercultural y Rondas Campesinas. En ese contexto fue presentado el Acuerdo Plenario No 1-2009/CJ-116 sobre Rondas Campesinas y el Derecho Penal, con la exclusiva finalidad de propiciar un abierto debate sobre sus alcances y contenidos ${ }^{20} 21$.

\subsection{Proyecto de Ley de Coordinación y Armonización Intercultural de la Justicia}

Cabe también hacer una breve reseña sobre la preocupación del Poder Judicial en cuanto a la dación de una nueva ley que contemplará la justicia de paz en el Perú, preocupación que fue reflejada en las declaraciones de cada congreso internacional que sobre justicia intercultural se ha llevado a cabo. Es así que finalmente se dio una Ley de Justicia de Paz, Ley $\mathrm{N}^{\circ} 29824$ en diciembre de 2011, y, su Reglamento mediante Decreto Supremo 007-2013-JUS, de 25 de junio de 2013.

Igualmente, cabe destacar que como iniciativa legislativa se presentó al Congreso de la República el Proyecto de Ley de Coordinación y Armonización

\footnotetext{
20 Prado Saldarriaga, Víctor. Ob. Cit., p. 175.

21 Son particularmente interesantes los análisis que efectúan GITLITZ (GITLITZ, John. «Una mirada desde la Sociología. Comentarios al Acuerdo Plenario de la Corte Suprema». En: La Facultad Jurisdiccional de las Rondas Campesinas. Instituto de Defensa Legal. Lima 2010, pp. 21 y ss.) y Ruíz MolledA (Ruíz MolLEDA, Juan Carlos: «Una mirada desde el Derecho Constitucional. Algunos Comentarios al Acuerdo Plenario de la Corte Suprema sobre Rondas Campesinas». En: La Facultad Jurisdiccional de las Rondas Campesinas. Instituto de Defensa Legal. Lima 2010, pp. 73 y ss.); sobre este Acuerdo Plenario.
} 
Intercultural de la Justicia (Proyecto de Ley 313/2011-PE), que fue aprobado para su presentación mediante Resolución Administrativa No 103-2011-SPCS-PJ, resolución de la Sala Plena de la Corte Suprema de Justicia de la República, de 29 de septiembre de 2011, visto el proyecto presentado por el doctor Víctor Roberto Prado Saldarriaga, lo cual es una cuestión pendiente y que en el IV Congreso Internacional de Justicia Intercultural se ha invocado al Congreso de la República para su aprobación y posterior implementación.

\subsection{Congresos Internacionales de Justicia Intercultural}

Por otra parte, una experiencia sumamente importante en el camino a la asunción de la justicia intercultural está constituida por los cuatro Congresos Internacionales sobre Justicia Intercultural en Pueblos Indígenas, realizados en La Merced, Cajamarca, Huaraz y Lima, en 2009, 2010, 2011 y 2012, respectivamente.

Resulta significativo lo expresado por el Presidente de la Comisión Organizadora de los tres primeros congresos, doctor Darío PALACIOS DEXTRE, quien señala que, "recientes sucesos de explosión social en poblaciones nativas, llevaron a las autoridades judiciales a reconocer la necesidad de fortalecer la presencia del Estado en aquellas comunidades donde el sistema de justicia formal comparte roles y espacios con la justicia comunitaria; relación harto compleja si advertimos que la interrelación entre ambos sistemas generan situaciones de conflicto e incluso de negación mutua de competencias, de no corresponder a las dinámicas culturales de cada pueblo". Complementa lo dicho precisando que "el imperativo de establecer niveles de coordinación entre el sistema de justicia ordinaria y los sistemas o subsistemas de justicia especial, nace de la necesidad de reducir la brecha cultural existente entre ambas; lo que plantea innumerables retos en cuanto a la comprensión del fenómeno social de la exclusión y el estudio de propuestas que reformulen tanto la legislación aplicable a los casos que involucren a integrantes de dichas poblaciones, como las competencias de las autoridades o instancias rurales encargadas de administrar justicia, particularmente en lo referente a sus procedimientos" 22 .

Observamos un pensamiento maduro de un Poder Judicial como poder del Estado, que afronta de manera decidida el fenómeno de la exclusión -en propias palabras del doctor PALACIOS- planteando una justicia inclusiva como

22 Palacios DeXtre, Darío. «Congresos Internacionales sobre justicia intercultural en pueblos indígenas, comunidades andinas y rondas campesinas». Fondo Editorial del Poder Judicial, Lima 2011 p.16. 
política pública que establezca mínimamente niveles de coordinación entre la justicia ordinaria y la justicia especial de los pueblos indígenas, comunidades andinas y rondas campesinas, teniendo en cuenta-sobre todo- que lo que hay que enfrentar desde la judicatura son aquellos seculares modelos culturales impuestos y relaciones de poder que subyacen al estado de cosas subyugante para la población indígena y campesina. Como manifiesta el doctor César SAN MARTíN, "se trata de todo un proceso ideado con el deliberado propósito de establecer firmes relaciones entre la justicia formal con las instancias de justicia comunal, donde prime el diálogo democrático, la participación activa y respeto mutuo, al momento de buscar puntos coincidentes o al abordar las diferencias culturales que en materia de justicia sean menester tratar. Ello obviamente implica abordar la dinámica aquí planteada desde una perspectiva de respeto de los derechos fundamentales" ${ }^{\prime 23}$.

El Primer Congreso se realizó -como ya se adelantó- en La Merced, Junín, del 28 de septiembre al 1 de octubre de 2010. En este se llegaron a acuerdos y recomendaciones valiosas incorporadas en lo que se denominó Declaración de La Merced. Así entre las conclusiones se tienen:

1. Este congreso constituye un hito histórico en el proceso de diálogo intercultural entre los sistemas de justicia ordinaria y la justicia indígena, el cual debe mantenerse y consolidarse.

2. Afirmamos que en nuestro país coexisten diversos pueblos que tienen sus propios sistemas jurídicos, los cuales resuelven todo tipo de conflictos dentro de su ámbito territorial, y fuera del mismo, entre sus miembros, de conformidad con su derecho consuetudinario.

3. En aplicación del artículo $149^{\circ}$ de la Constitución Política, el Convenio $N^{\circ} 169$ de la Organización Internacional del Trabajo, la Declaración de Naciones Unidas sobre derechos de los Pueblos Indígenas, y el artículo $18^{\circ} .3$ del Código Procesal Penal, la jurisdicción ordinaria debe respetar plenamente los sistemas jurídicos indígenas.

4. Manifestamos nuestra voluntad de entrar en relaciones de coordinación y diálogo intercultural entre ambas jurisdicciones.

5. Respaldar la iniciativa del Presidente del Poder Judicial, Dr. Javier Villa Stein, por promover espacios de diálogo con los pueblos indígenas a través de este tipo de encuentros.

\footnotetext{
${ }^{23}$ SAN MARTín, César. "Congresos Internacionales sobre justicia intercultural en pueblos indígenas, comunidades andinas y rondas campesinas». Fondo Editorial del Poder Judicial, Lima 2011, p. 11.
} 
Asimismo, las recomendaciones del evento fueron:

1. Crear, en los distritos judiciales, instancias de coordinación entre la justicia ordinaria e indígena, de composición paritaria, mixta intercultural, con representantes indígenas designados por ellos mismos.

2. Establecer los mecanismos y criterios de coordinación entre los sistemas de justicia ordinaria y la justicia indígena en el marco de un diálogo intercultural, con participación de las autoridades de ambas jurisdicciones.

3. Identificar los procesos judiciales que involucran a indígenas y los casos de conflicto entre la jurisdicción ordinaria e indígena, para efectos de que se respeten los derechos indígenas y se realicen las coordinaciones que permitan dar las soluciones correspondientes.

4. Sistematizar la jurisprudencia de la jurisdicción ordinaria en materia de pueblos indígenas y diversidad cultural; así como las distintas experiencias de los sistemas jurídicos indígenas.

5. Generar espacios de formación, capacitación e intercambio de saberes con enfoque intercultural para los operadores de justicia ordinaria y de autoridades de la jurisdicción indígena, con participación paritaria.

6. Plantear al Congreso de la República la convocatoria de la consulta previa a los pueblos indígenas para el desarrollo legislativo del artículo $149^{\circ}$ de la Constitución Política que comprenda, entre otros, el fortalecimiento de la jurisdicción indígena, el reconocimiento de los derecho y beneficios sociales de las autoridades de dicha jurisdicción y la dotación de los recursos que requieren para su buen funcionamiento.

Por otra parte, el Segundo Congreso se realizó en la ciudad de Cajamarca, del 8 al 10 de diciembre de 2010, tomándose como conclusiones:

1. Este Segundo Congreso viene a consolidar y ratificar las conclusiones del primer Congreso Internacional sobre Justicia Intercultural en Pueblos Indígenas, realizado en la ciudad de La Merced - Chanchamayo, por lo que constituye una renovación del compromiso del Poder Judicial para desarrollar este proceso de acercamiento y de encuentro entre la justicia ordinaria y la justicia especial comunal y ronderil, en el marco del diálogo intercultural. 
2. Reconocemos el importante papel que cumplen las comunidades y rondas campesinas en el ejercicio de sus funciones jurisdiccionales, contribuyendo de esa forma al objetivo común de lograr la paz social y el mejor acceso a la justicia de la población rural.

3. Afirmamos la necesidad de construir procesos para que la justicia ordinaria y la justicia comunal y ronderil desarrollen mecanismos para promover relaciones de complementariedad y mutuo apoyo.

4. Ratificar el respeto y cumplimiento de la legislación nacional e internacional sobre los derechos de los pueblos indígenas y rondas campesinas a efectos de su debida observancia por las autoridades del sistema de justicia.

5. Reiteramos nuestro reconocimiento al papel protagónico desempeñado por el Doctor Javier Villa Stein, en su condición de Presidente de Poder Judicial, por haber propiciado la reflexión sobre la justicia intercultural en estos dos Congresos, y le solicitamos al Presidente Electo Doctor César San Martín Castro que continúe profundizando la agenda desarrollada en el marco del diálogo intercultural, entre la justicia ordinaria y la justicia comunal.

Asimismo, se adoptaron las recomendaciones siguientes:

1. Fortalecer los mecanismos y criterios de coordinación entre los sistemas de justicia ordinaria y la justicia indígena, en el marco de un diálogo intercultural, con participación de las autoridades de ambas jurisdicciones.

2. Solicitar al Congreso de la República la aprobación de la Declaración de las Naciones Unidas sobre Derechos de los Pueblos Indígenas, del 13 de septiembre de 2007.

3. Crear una Oficina Nacional de Justicia Intercultural, dependiente del Poder Judicial, para desarrollar políticas de coordinación entre la jurisdicción estatal, comunal y ronderil.

4. Generar espacios de formación, capacitación e intercambio de saberes con enfoque intercultural para los operadores de justicia ordinaria y de las autoridades de la jurisdicción indígena, con participación paritaria, replicando la experiencia de los Centros de Justicia Intercultural de los Distritos Judiciales de San Martín y Cajamarca. 
5. Recomendar a las autoridades educativas de todos los niveles de educación, la creación de cursos que promuevan el estudio y la reflexión de la diversidad cultural del Perú, con el fin de impulsar la comprensión intercultural en nuestra sociedad.

6. Recomendar que, en las zonas declaradas en estado de emergencia, se afirme la plena vigencia de los derechos humanos y, asimismo, se respete el derecho de las Comunidades Indígenas y Rondas Campesinas.

Por otra parte, en el Tercer Congreso, realizado en Huaraz del 27 al 30 de noviembre de 2011, se arribaron a las siguientes conclusiones y recomendaciones:

1. El actual Congreso consolida las conclusiones y recomendaciones del I y II Congresos Internacionales sobre Justicia Intercultural en Comunidades Nativas, Comunidades Campesinas y Rondas, realizados en las ciudades de La Merced y Cajamarca, respectivamente, por lo que constituye una ratificación del proceso de acercamiento y de encuentro entre la justicia ordinaria y la justicia especial comunal y ronderil.

2. Confirmamos la importancia de las comunidades campesinas, comunidades nativas y rondas como instituciones que imparten justicia en el mundo rural peruano, contribuyendo con la paz social y el mejor acceso a la justicia de aquella población.

3. Reconocemos el esfuerzo del Poder Judicial para asumir como enfoque y política institucional a la interculturalidad en la justicia, para, en base a ella, orientar la actuación de sus instancias y órganos jurisdiccionales.

4. Declaramos que el respeto mutuo entre el Poder Judicial y la justicia indígena es la base primordial para continuar el proceso de coordinación en marcha de manera sostenible.

5. Los jueces del Poder Judicial reconocen en la diversidad de formas de justicia comunal y ronderil la aplicación de un conocimiento valioso, distinto y dinámico, y manifiestan su voluntad de esforzarse en conocerlo con mayor detalle.

6. Respaldamos el Proyecto de Ley 313/2011-PE, sobre coordinación intercultural de la justicia, y ofrecemos nuestra continua y abierta reflexión para su mejora, aprobación y aplicación práctica. Asimismo, saludamos la 
Víctor Malpartida Castillo - Poder Judicial, justicia inclusiva y justicia intercultural

decisión adoptada por el Congreso de la República al aprobar el proyecto de ley sobre Justicia de Paz presentado por el Poder Judicial.

7. Resulta necesario desarrollar un Protocolo de Gestión a aplicarse por la justicia ordinaria que le permita una adecuada investigación y juzgamiento, de aquellos casos en que estén inmersos los miembros de las comunidades campesinas, comunidades nativas y rondas.

8. Es necesario que se implementen acciones de sensibilización y capacitación a nivel nacional desde el Poder Judicial para que los jueces conozcan y apliquen el nuevo marco jurídico que reconoce la jurisdicción especial indígena.

9. Se convoca la participación activa en el desarrollo de la política de justicia intercultural a las instituciones del sistema de justicia, o vinculadas con esa labor: Ministerio Público, Tribunal Constitucional, Defensoría del Pueblo, Consejo Nacional de la Magistratura, Academia de la Magistratura, Ministerio de Justicia y Policía Nacional del Perú.

10. Reconocemos las dificultades que cada sistema de justicia tiene para cumplir sus diversas visiones y fines, aunque, a la vez, encontramos grandes afinidades entre ellas vinculadas con la paz, el derecho al desarrollo y la promoción del ser humano, lo cual permite confiar en la posibilidad y eficacia de la colaboración.

11. Destacamos que la riqueza de la pluralidad actualmente existente es afectada por la carencia de medios económicos que impiden su mejor articulación, por lo que el Poder Judicial, como líder del Sistema de Justicia, exhorta a las autoridades de los poderes Ejecutivo y Legislativo a aprobar aquellas medidas que, de no ponerse en vigencia, van a afectar la mejor gestión de su presupuesto, pues ello repercute inmediatamente en los ciudadanos, y de manera particular en los más vulnerables, entre quienes se cuentan las personas y comunidades indígenas.

12. Lamentamos el indebido uso de la violencia en Cajamarca, mientras se realiza este Congreso, y las heridas físicas y sociales que ella produce, e invocamos que se recurra al diálogo para resolver las diferencias actualmente existentes.

13. Expresamos nuestro reconocimiento al Doctor César San Martín Castro, Presidente del Poder Judicial, por su compromiso con la justicia 
intercultural, promoviendo una posición institucional del Poder Judicial favorable a la coordinación y colaboración con la justicia indígena, en un contexto de interculturalidad y de protección efectiva de los derechos humanos.

Y, finalmente, en la denominada Declaración de Lima, como corolario del IV Congreso Internacional sobre Justicia Intercultural, realizado del 13 al 15 de diciembre de 2012, se pueden resaltar, entre otros aspectos, la invocación "a las Cortes Superiores a desarrollar y fortalecer los mecanismos y criterios de coordinación entre los sistemas de justicia ordinaria y especial". Asimismo, cabe señalar la recomendación que se hace de crear en cada Corte Superior, una escuela de justicia intercultural, así como la creación de una Escuela Nacional de Justicia Intercultural; igualmente resulta sumamente interesante, la propuesta de la aprobación e implementación de una Hoja de Ruta de Justicia Intercultural.

Del anterior recuento de lo concluido en los cuatro Congresos de Justicia Intercultural habidos hasta la actualidad, fluye una decidida apuesta del Poder Judicial por la interculturalidad desde un primer señalamiento en La Merced de lo pertinente de un diálogo intercultural entre la justicia ordinaria y la justicia indígena, luego ratificado en Cajamarca, y auspiciar la propuesta de una política institucional de la interculturalidad en la justicia, en Huaraz, lo cual significa la asunción de una política pública de justicia intercultural, lo que implica un despliegue de recursos presupuestados, pero asimismo, y a nuestro parecer lo más importante, internalizar un pensamiento de pluralismo jurídico y de diálogo democrático entre culturas horizontal, lo que es ratificado en la Declaración de Lima de diciembre de 2012, al considerarse la propuesta de una Hoja de Ruta de Justicia Intercultural. Como aspecto final puede también puntualizarse que se proclama el respeto de los derechos de los pueblos indígenas.

Todo ello hace que se pueda hablar de un nuevo momento del Poder Judicial en relación a los pueblos indígenas y en el asumir decididamente el pluralismo jurídico, lo cual es consecuencia de varios instantes previos que hemos hecho el recuento aquí ${ }^{24}$.

\footnotetext{
${ }^{24}$ La función del Poder Judicial estará encuadrada en -previamente- reconocer cuál es el origen y cuál es el carácter del pluralismo subyacente al pluralismo jurídico. Así, es necesario tener en cuenta lo señalado por HABERMAS -con los cuidados ideológicos que debe tenerse-, en cuanto plantea que debe establecerse primero si estamos ante un Estado en el que "las minorías endógenas se hacen conscientes de su identidad" o de Estados en donde "surgen nuevas minorías por causa de la inmigración", "dependiendo de si con esa tarea se confrontan Estados que, en razón de su historia y de su cultura política, se comprenden a sí mismos como un Estado de inmigración o como un Estado cuya autocomprensión nacional debe ser adaptada a
} 


\section{PLURICULTURALIDAD, MULTICULTURALIDAD E INTER- CULTURALIDAD}

Visto lo anterior, se hace imprescindible establecer los conceptos y las diferencias entre pluriculturalidad, multiculturalidad e interculturalidad.

Ahora bien, un concepto anterior a los tres señalados y asimismo, sin el cual, no pueden entenderse en toda su dimensión, es el concepto de cultura.

Así, se tiene el concepto de Clifford GEERTZ, para quien la cultura " (...) denota un esquema históricamente transmitido de significaciones representadas en símbolos, un sistema de concepciones heredadas y expresadas en formas simbólicas por medios con los cuales los hombres comunican, perpetúan y desarrollan su conocimiento y sus actitudes frente a la vida". Este concepto a su vez se funda en dos ideas. La primera en cuanto a que "(...) la cultura se comprende mejor no como complejos de esquemas concretos de conductacostumbre, usanzas, tradiciones, conjunto de hábitos-, como ha ocurrido en general hasta ahora, sino como una serie de mecanismos de control-planes, recetas, fórmulas, reglas, instrucciones (lo que los ingenieros de computación llaman "programas") que gobiernan la conducta (...)". Y, asimismo, la segunda "es la de que el hombre es precisamente el animal que más depende de esos mecanismos de control extragenéticos, que están fuera de su piel, de esos programas culturales para ordenar su conducta" 2526.

\footnotetext{
la integración de culturas extrañas". Esto es fundamental para HABERMAS, en tanto dependiendo de una u otra situación va a dar lugar a un mayor o menor desafío iniciado por las sociedades multiculturales o pluriculturales. Así, "los desafíos resultarán mayores cuanto más profundas sean las diferencias de religión, de raza o de etnia o las diacronías histórico - culturales que deben ser superadas; serán más dolorosos cuanto más adopten las tendencias de autoafirmación un carácter fundamentalista-delimitador, ya sea porque la minoría que pugna por el reconocimiento al haber sufrido experiencias de impotencia se refugie en regresiones, o ya sea porque tenga que despertar por vía de una movilización de masas a la conciencia de la articulación de una nueva identidad elaborada constructivamente" (HABERMAS, Jürgen. «La inclusión del otro. Estudios de teoría política». Paidós, Barcelona 1999, p.199).

25 RIVERA Vela, Enrique: «La interculturalidad como principio ético para el desarrollo de nuestros pueblos». Instituto Nacional de Ciencia y Ética. Arequipa, junio 2009, pp. 10-11.

${ }^{26}$ Interesante resulta citar lo que sobre cultura expresa Ralph LiNTON: "(...) No debemos dejar de reconocer que estas facultades humanas, cuyos orígenes pueden encontrarse en el nivel animal, han producido por su interacción algo nuevo y único. Es posible demostrar que cada pieza de un automóvil moderno es modificación o ampliación de algún útil empleado antes de aparecer el automóvil; sin embargo, éste es, en sí, algo nuevo y distinto. Del mismo modo la cultura humana, aunque desarrollada sobre un fondo animal, difiere de todo cuanto puede encontrarse entre los animales. Ha sido producida por una especie dentro de los mamíferos, pero, a su vez, ha hecho humana a esa especie. Sin la existencia de la cultura, gracias a la cual se conservan las adquisiciones del pasado y se modelan las generaciones sucesivas de acuerdo con sus patrones, el homo sapiens no sería más que un mono antropoide terrícola, ligeramente distinto en estructura y algo superior en inteligencia, pero hermano del chimpancé y del gorila" (LINTON, Ralph. "Estudio del Hombre». Fondo de Cultura Económica, Séptima edición, México 1963, pp. 90-91).
} 
De esto entonces, se puede desprender -siguiendo a RIVERA VELA- que "la cultura incluye la cosmovisión y los principios axiológicos, que son los elementos que dan identidad a un pueblo y sobre los cuales se ha creado lo visible de las culturas: sus manifestaciones materiales (música, tradición oral, religión, etc.), así como los comportamientos propios de cada pueblo" 27 .

Asimismo, Fernando SILVA SANTISTEBAN ${ }^{28}$ señala que la cultura es un concepto para designar a un conjunto de fenómenos que caracterizan al tipo de actitud exclusivamente humana surgida de la capacidad de poder reflejar la realidad objetiva en forma de imágenes ideales las que, al mismo tiempo, se convierten en objeto de conciencia para el hombre. Pero -agrega el profesor- si bien es cierto que el concepto que tenemos de cultura es el resultado de la aprehensión racional de una relación o sistema de fenómenos sociales, es dependiente de la capacidad cognoscitiva y de la manera como son captados aquellos aspectos de la realidad objetiva. Las condiciones sociales de la existencia humana son reales -aclara-, pero su percepción puede ser incompleta, irregular, inadecuada en todo una serie de acciones e, incluso, ilusoria. Aquí radica su relatividad -especifica el autor citado-, puesto que es muy posible que muchos aspectos de la realidad social no hayan sido aún advertidos. Prueba de ello es la variación que a través de tiempo y según como se ha desarrollado la observación ha sufrido el propio término cultura,

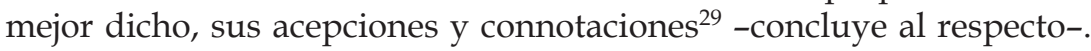

Por otro lado, Diez Hurtado, nos habla que hay dos concepciones históricas del término cultura. Así, aquella que proviene de la Revolución Francesa que en el siglo XIX entendía por cultura a la civilización, como los logros humanos, propios de la humanidad, un estado superior de la evolución. La segunda proviene de la tradición alemana, la cual entiende a la cultura como la cualidad innata de cada grupo humano, una especie de esencia, que hace

\footnotetext{
27 Rivera Vela, Enrique. Ob. Cit., p. 11.

28 Silva SANTISTEBAN, Fernando. «Antropología. Concepto y nociones generales». Universidad de Lima, Primera edición, Lima 1977, p. 135. En otro texto, el Profesor SILVA SANTISTEBAN acota: "La cultura, como resultado de la interacción entre grupos sociales y la naturaleza exterior, o de esos grupos con otros grupos sociales, se revela como un conjunto de rasgos y productos de actividad social que denotan la especificidad de un determinado grupo social humano. Es entonces cuando se objetivan las realizaciones colectivas y nos referimos a ellas como a "una cultura concreta y determinada, que existe, o que ha existido en determinado tiempo y en determinado lugar; así, hablamos de cultura minoica o de cultura incaica y, ampliando más los alcances del término, podemos hablar de civilización occidental o de civilización andina, ya que la civilización no es otra cosa que el grado máximo de desarrollo y complejidad de la cultura (...)" (SILVA SANTISTEBAN, Fernando. "Introducción a la Antropología Jurídica». Universidad de Lima - Fondo de Cultura Económica- Perú, Primera edición, Lima 2000, pp. 58-59).

29 GUARDiA MAYORGA define cultura de la siguiente manera: “(...) es el conjunto de producciones materiales e intelectuales que efectúa el hombre en el proceso de su desarrollo social e histórico".(GUARDIA MAYORGA, César. Cultura Humana, Lima 1966, p. XII).
} 
diferentes y particulares a cada grupo humano con respecto a otro. Se señala asimismo, que nuestros usos contemporáneos y coloquiales contienen ambos conceptos divergentes.

Por todo lo anterior, el profesor antes nombrado, concluye que "la cultura es al mismo tiempo algo propio a los seres humanos, algo que nos diferencia de los animales, y algo que nos hace diferentes unos a otros" ${ }^{\prime \prime 30}$.

Ahora bien, concluye el autor citado que se pueden establecer tres componentes en lo que respecta a la cultura, sobre los que existe cierto consenso. A saber:

1. La cultura no es un asunto de raza, se aprende, no se lleva en los genes. La cultura está vinculada a los procesos de socialización humana, a la forma como los individuos se integran a su sociedad a lo largo de su vida.

2. Aunque de manera desigual, la cultura humana ha progresado en el largo plazo, hay avances tecnológicos irreversibles que conectan a las diversas culturas.

3. La cultura es esencialmente una cuestión de ideas y valores, un molde mental colectivo y compartido, por lo que se puede describir la cultura como un sistema simbólico.

Es entonces en base a lo anteriormente expuesto, que DiEZ HuRTADO precisa que el supuesto básico del enfoque más utilizado de cultura en las discusiones sobre interculturalidad -lo que nos interesa realmente- es que "cultura" corresponde a una comunidad, a una colectividad distinguible de las otras, con rasgos característicos. En palabras del autor citado, el enfoque más utilizado de cultura finalmente en relación con la interculturalidad, es la primera acepción pero que se desarrolla sobre la segunda. Parte de que todas las culturas tienen un mismo estatus, pero reconoce a su vez, la distinción entre ellas.

Asimismo, pluriculturalidad, es una categoría utilizada - como manifiesta Rivera Vela ${ }^{31}$ a quien seguimos en esta parte mayormente - para caracterizar la situación en la que al interior de un mismo territorio co-existen varios grupos humanos con culturas diferentes, siendo el ideal que la relación

\footnotetext{
${ }^{30}$ Diez HuRTADO, Alejandro. «Entre la cultura y la interculturalidad». En: La interculturalidad como principio ético para el desarrollo de nuestros pueblos. Instituto Nacional de Ciencia y Ética; Arequipa, junio 2009, pp. 20 y ss.

31 Rivera Vela, Enrique. Ob. Cit., p.12 y ss.
} 
existente entre ellos sea de reconocimiento mutuo y respetando sus diferencias culturales, aunque no siempre sea así.

De otra parte, multiculturalidad representa una propuesta que tiene su origen en los países del norte, específicamente en Estados Unidos de Norteamérica. Su concepción -precisa RIVERA VELA- parte de la existencia de diversos grupos humanos con rasgos culturales claramente definidos (anglosajones, chinos, latinoamericanos, africanos, etc.) compartiendo un espacio común y en el que, aunque existan comportamientos tolerantes, no llegan a establecerse relaciones dinámicas entre las culturas. Este modelo representa ante todo -aclara el autor- una propuesta donde se marcan diferencias por la autoproclamada superioridad de la cultura receptora y la supuesta inferioridad de las otras.

Asimismo, la interculturalidad se emplea para referirse a la convivencia armónica, dialogante y no excluyente en miras de construir o desarrollar proyectos políticos comunes a largo plazo, respetando las diferencias culturales de los grupos humanos involucrados ${ }^{32}$ 33. Es así que Catherine WALSH señala sobre la interculturalidad lo siguiente: "Como concepto y práctica, la interculturalidad significa "entre culturas", pero no simplemente un contacto entre culturas, sino un intercambio que se establece en términos equitativos, en condiciones de igualdad. Además de ser una meta por

32 ZÚÑIGA y ANSIÓN plantean la diferencia entre "mestizaje cultural" e interculturalidad señalando: "En términos más teóricos, se critica también esta noción ("mestizaje cultural") porque - como lo señalara Fernando Fuenzalida - trata las culturas como si fueran entidades corpóreas con capacidad de mezclarse de modo similar a los seres orgánicos. para nosotros, en cambio, la cultura no tiene existencia en sí misma, sino que se refiere a actitudes acostumbradas y a maneras de ser compartidas (dimensión social) de las personas en concreto (dimensión individual). Por esta razón, en el mejor de los casos, podría hablarse de "mestizaje" en un sentido metafórico, pero es una metáfora que, lejos de ayudar a entender la realidad, más bien conduce a confundirla" Agregan. "Por todo ello, nos parece más provechoso dejar de lado ese término para centrarnos en lo que realmente importa: el estudio de las transformaciones que ocurren en nosotros - y que compartimos con otros - al entrar en contacto permanente con personas y grupos que suelen expresarse, actuar, pensar o sentir de modo distinto al que acostumbramos. Lo importante es entender de qué manera, en el contacto cotidiano entre grupos de orígenes distintos, ocurre las transformaciones sociales y cómo van de la mano con cambios en las mentalidades, en los universos simbólicos, en el imaginario de las personas, en sus maneras de sentir y percibir el mundo y, en especial, en sus maneras de adaptarse y enfrentar situaciones nuevas, de relacionarse con datos culturales distintos a los propios"(ZÚÑIGA CASTILLO, Madeleine y ANSIÓN MALLET, Juan: Interculturalidad y educación en el Perú. Foro Educativo, Lima 1997).

33 Se debe mencionar además que se habla también de una filosofía intercultural: "(...) a diferencia de la Filosofía occidental europea cuya esencia reside en que sólo dialoga con ella misma, es decir, que practica un monólogo con los representantes de su propia cultura, la Filosofía Intercultural se abre a todas las demás culturas, comunica sus saberes, escucha respetuosamente y al mismo nivel que sí misma, a las demás culturas; confronta, debate, y, el Otro deja en ellas una estela de inquietudes intranquilizantes, semillero hormigueante de nuevas posibilidades de expresiones filosóficas"(VIDAL ALVA, Dora. «La Filosofía Intercultural y la Filosofía latinoamericana». En: Reflexión y Crítica. Revista de Filosofía. Año 7 N³. Departamento Académico de Filosofía, Facultad de Letras y Ciencias Humanas, Universidad Nacional Mayor de San Marcos, Lima 2003, p.60). 
alcanzar, la interculturalidad debería ser entendida como un proceso permanente de relación, comunicación y aprendizaje entre personas, grupos, conocimientos, valores y tradiciones distintas, orientadas a generar, construir y propiciar un respeto mutuo, y a un desarrollo pleno de las capacidades de los individuos, por encima de sus diferencias culturales y sociales. En si, la interculturalidad intenta romper la historia hegemónica de una cultura dominante y otras subordinadas y, de esa manera, reforzar las identidades tradicionalmente excluidas para construir, en la vida cotidiana, una convivencia de respeto y de legitimidad entre todos los grupos de la sociedad".

De manera que el término pluriculturalidad es uno de carácter descriptivo, que nos muestra una situación específica de existencia de varios grupos humanos con sus correspondientes culturas distintas; y, asimismo, en lo que respecta a la multiculturalidad, también existe una situación de grupos y culturas distintas, pero no obstante que éste término alude a tolerancia y respeto entre dichas culturas, también es cierto que hay una intencionalidad en el mencionado término en cuanto a que va a existir una cultura dominante y otras subordinadas, es decir, hay una relación de poder entre ellas. En el caso de la interculturalidad, por el contrario, se parte también de la misma situación pero como manifiesta WALSH, la interculturalidad es un proceso y también una meta, vale decir, el proceso es el diálogo e intercambio entre las culturas diferentes en una situación de igualdad y, en tanto meta, es acabar con una situación de dominio y subordinación entre dichas culturas ${ }^{34}$.

De allí que Carlos Iván Degregori, de manera bastante gráfica plantee que, atendiendo a la caracterización de una sociedad como la peruana, sea más acorde utilizar un término como el de interculturalidad que el de multiculturalidad:

\footnotetext{
34 Tubino señala: Mientras que el culturalismo, la palabra es tolerancia, en la interculturalidad "la palabra clave es diálogo. La interculturalidad reasume en parte de multiculturalismo, en el sentido de que para dialogar hay que presuponer respeto mutuo y condiciones de igualdad entre los que dialogan" (ETXEBERRIA). En otras palabras la interculturalidad como propuesta ético-política presupone el multiculturalismo, es decir, la reducción de las relaciones asimétricas entre las culturas. Podemos plantearlos también en términos conceptuales y decir que la interculturalidad presupone a veces el multiculturalismo así como el diálogo intercultural presupone la tolerancia. La tolerancia negativa consiste en no hacer "de una creencia propia una condición absoluta de la convivencia" (THIBEAUT)". (TUBINO, Fidel. "Entre el multiculturalismo y la interculturalidad: más allá de la discriminación positiva». p. 25). Por otra parte INDEPA dice: "no olvidemos que la interculturalidad es el contacto establecido y conformado por agentes de distintas culturas, los cuales buscan de forma horizontal acuerdos y prácticas, añadiendo selectivamente algunos aportes culturales de cada uno, en función de tareas comunes, buscando objetivos para mejorar la eficacia y equidad de las mismas; propiciando así la identificación con la gestión mancomunada" (INDEPA. "Aportes para un enfoque intercultural». Lima 2010, p.74).
} 
“Dentro de las concepciones multiculturales que se vienen desarrollando en los países del Norte, los diferentes nosotros son vistos como bloques bien definidos, con fronteras muy precisas, y donde el ideal es que las contradicciones, roces y diferencias se solucionen vía la tolerancia y el respeto, y donde la acción afirmativa consiste en que $\mathrm{B}$ y C, que están más abajo que $\mathrm{A}$, sean empujados o impulsados para equipararse con A y estar al mismo nivel de desarrollo económico o de poder.

"Yo creo que esta política es aplicable a realidades como la norteamericana donde, por razones históricas, se han conseguido logros importantes en términos de tolerancia, reconocimiento y acción afirmativa. Sin embargo, creo que para realidades como la peruana, la aproximación intercultural es mucho más rica porque implica que, $\mathrm{A}, \mathrm{B}$ y $\mathrm{C}$ no son bloques diferenciados, ni con fronteras nítidas, y donde las relaciones de poder que existen desde hace muchos siglos -que son las que hay que cambiar- son el resultado de una interacción en la cual no puede entenderse A sino en su relación con $\mathrm{B}$ y con $\mathrm{C}$, y donde el resultado nunca es final porque la interrelación continúa. No existimos si no es a través y por la existencia de los otros y mediante las miradas mutuas. Las soluciones, por lo tanto, no pueden ser iguales para ambas realidades.

"En nuestro caso, lo ideal sería establecer miradas horizontales entre A, B y C, donde el poder sea más o menos equiparado, y tender hacia una interculturalidad sana y humanista donde se pueda vivir feliz todas las patrias, utopía arguediana considerada arcaica por VARGAS LLOSA, a pesar de estar tan ligada a las discusiones actuales" ${ }^{\prime 35}$.

Tiene, por tanto, indudables ventajas un enfoque de interculturalidad. Se señala que el logro de la autoestima equilibrada a nivel grupal e individual, consiste en valorarse a uno mismo, acoger lo propio con aprecio y, al mismo tiempo, engendrar en uno mismo una actitud de apertura a lo externo. Esta es precisamente la condición de una comunicación intercultural: “Dicha apertura permitirá valorar también lo ajeno y esta valoración permitirá incorporarlo, integrándolo y no asimilándose a él, recreándolo y reinventando así la cultura propia. De esta manera se le abre la posibilidad a un grupo cultural de seguir viviendo, sin anquilosarse en el culto al pasado ni eliminarse a sí mismo en la negación de lo propio" ${ }^{\prime 36}$.

\footnotetext{
35 DegregorI, Carlos Iván. «Multiculturalidad e Interculturalidad», p.2.

${ }^{36}$ HeISE, María; Tubino, Fidel; y Wilfredo ARDITO. «Interculturalidad. Un desafío». p.8.
} 


\section{BASE JURÍDICA DE LA JUSTICIA INTERCULTURAL}

El contexto jurídico en el que se desenvuelve la justicia intercultural en el Perú actualmente, tiene como aspectos resaltables, en primer lugar, lo establecido en la Constitución Política, de 1993. Así, se ha establecido que "toda persona tiene derecho a: su identidad étnica y cultural. El Estado reconoce y protege la pluralidad étnica y cultural de la Nación" (artículo $2^{\circ}$ inc. 19); igualmente, se prescribe que "el Estado respeta la identidad cultural de las Comunidades Campesinas y Nativas"(artículo $89^{\circ}$ ); y finalmente se establece que "las autoridades de las Comunidades Campesinas y Nativas, con el apoyo de las Rondas Campesinas, pueden ejercer las funciones jurisdiccionales dentro de su ámbito territorial de conformidad con el derecho consuetudinario, siempre que no violen los derechos fundamentales de la persona. La ley establece las formas de coordinación de dicha jurisdicción especial con los Juzgados de Paz y con las demás instancias del Poder Judicial" (artículo 149 ${ }^{\circ}{ }^{37}$. Lo anterior va a ser complementado por la Ley No 24571 (Primera Ley de Rondas Campesinas) y la Ley $N^{\circ}$ 27908, Ley de Rondas Campesinas, así como la Ley No 24656, Ley General de Comunidades Campesinas y su Reglamento (Decreto Supremo No 008-91-TR).

De otro lado, se encuentra el Convenio 107 de la Organización Internacional del Trabajo (OIT), relativo a la Protección e Integración de las Poblaciones Indígenas y de otras Poblaciones Tribales y Semitribales en los países independientes, de 1957. También el Convenio 169 de la OIT, ratificado por el Perú en 1993, el cual trae como consecuencia la legitimidad del derecho consuetudinario y una figura, como son los pueblos indígenas. Cabe resaltar que dos aspectos principales son resaltados en este instrumento, y son, de una parte, el respeto de lo que constituye la cultura, instituciones, formas de vida de los pueblos indígenas, y de otra, la participación y consulta de los mencionados pueblos en las decisiones que van a afectarles. Son aspectos sustanciales en la interpretación del Convenio. Ligado al Convenio, se debe citar la Ley del Derecho a la Consulta Previa a los Pueblos Indígenas u Originarios aprobada en 2011.

Igualmente se debe tener en consideración la Declaración de las Naciones Unidas sobre los Derechos de los Pueblo Indígenas, Resolución de Asamblea General 61/295, del 13 de septiembre de 2007.

\footnotetext{
37 Se puede leer al respecto: IRIGOYEN FAJARDO, Raquel: «Retos para construir una juricidad pluricultural» (Balance de los proyectos de Ley sobre el art. $149^{\circ}$ de la Constitución)". En: BIRA. Boletín del Instituto Riva Agüero. N²8. Pontificia Universidad Católica del Perú, Lima 2001, pp. 153 y ss.
} 
Asimismo, cabe mencionar lo dispuesto en el artículo $15^{\circ}$ del Código Penal peruano vigente, el que prescribe: "El que por su cultura o costumbres comete un hecho punible sin poder comprender el carácter delictuoso de su acto o determinarse de acuerdo a esa comprensión, será eximido de responsabilidad. Cuando por igual razón, esa posibilidad se halla disminuida, se atenuará la pena". Al respecto cabe precisar que si bien para muchos este artículo ofrece una oportunidad de tomar conciencia de aquellos grupos con una cultura distinta o diversa también existen las críticas muy duras al mismo ${ }^{38}$.

También se debe anotar, el artículo 18 inc. 3 del Nuevo Código Procesal Penal, Decreto Legislativo $N^{0}$ 957, en el que se establece que la jurisdicción penal ordinaria no es competente para conocer de los hechos punibles en lo casos previstos en el artículo $149^{\circ}$ de la Constitución ${ }^{39}$.

Por otra parte, en cuanto a jurisprudencia, tenemos, en primer lugar, lo resuelto por la Corte Interamericana de Derechos Humanos en el caso Pueblo Indígena Kichwa de Sarayaku vs. Ecuador, sentencia de 27 de junio de 2012.

Asimismo, en el ámbito constitucional nacional, como aprecia César LANDA, desde el 2004 en el Tribunal Constitucional peruano, se vienen resolviendo algunas causas sobre el derecho al medio ambiente y los derechos de los pueblos indígenas, considerando los valores constitucionales y democráticos de la unidad y diversidad cultural ${ }^{40}$.

${ }^{38}$ Es el caso de Antonio PEÑA quien señala: "Nótese que se otorga al supuesto inculpado de una cultura diferente una especie de "perdón" por considerar que desde su "diferente cultura" (diríamos "inferior" o sometida al juzgador) no pudo comprender el carácter delictuoso del acto. En un estudio anterior ya hemos señalado: “...La solución penal propuesta no deja de ser parcial y hasta etnocéntrica frente al problema: consideramos "error" u "hecho punible" aquello que puede identificar como elemento cultural a un grupo étnico o social determinado, y, de otro lado, el problema de "incomprensión" del hecho delictivo corresponde ser probado - con mucha rigurosidad por el inmigrante involucrado (o persona involucrada) mientras sus juzgadores - por tratarse de materia penal - pertenecen a la autoridad central, esto es el juez penal del poder judicial estatal..."”. (PEÑA JUMPA. Antonio: «La interculturalidad en su aplicación en el derecho y la justicia: la aplicación de los derechos fundamentales y la justicia comunal en la Constitución peruana». En: La interculturalidad como principio ético para el desarrollo de nuestros pueblos. Instituto Nacional de Ciencia y Ética. Arequipa, junio 2009, p. 127. Como estudio histórico al respecto puede verse: PONCE DE LEÓN, Francisco. «Situación jurídico penal de los aborígenes peruanos». Cuzco 1948.

$39 \mathrm{Al}$ respecto puede leerse: BAZÁN CERDÁN, Jorge Fernando. «El Nuevo Código procesal Penal del 2004 y las Rondas Campesinas: Escenarios de Conflictividad y de Coordinación». Poder Judicial, Segunda edición, Lima 2011.

${ }^{40}$ LANDA señala los siguientes casos como importantes en relación con la interculturalidad: STC $\mathrm{N}^{\circ} 042-$ 2004-AI/TC (impuesto de las corridas de toros) y STC No 00017-2010-AI/TC (sobre materia similar a lo anterior); STC Nº 03343-2007-PA/TC (Cordillera Escalera); STC Nº 04611-2007-PA/TC (derecho al honor de las comunidades nativas); STC N 0022-2009-PI/TC (Inconstitucionalidad del Régimen de Formalización y Titulación de Tierras Rurales- D.Leg. 1089), STC N 06316-2008-PA/TC (Pueblos Indígenas No Contactados) y STC N 05427-2009-PC/TC (Cumplimiento del Convenio OIT N 169) (LANDA, César: «Interculturalidad en la jurisprudencia del Tribunal Constitucional». En: Anuario de Derecho Penal 2010. Sistema de control penal y diferencias culturales. Director: José HurTAdo POZO. Pontificia Universidad Católica del Perú - Universidad de Friburgo Suiza, Lima 2012, pp. 101 y ss.). 
También, cabe hacer mención de múltiples sentencias expedidas por las Salas de la Corte Suprema de la República, en las que contemplan casos de justicia intercultural en cuanto a la actuación de las comunidades y rondas campesinas $^{41}$.

\section{A MANERA DE CONCLUSIÓN: INTERCULTURALIDAD COMO PROCESO INCLUSIVO Y COMO META}

Todo lo anterior no hace sino reafirmar que se ha constituido en el Perú un reconocimiento a un cierto pluralismo jurídico, en el que los derechos de las comunidades constituyen una especie de subsistemas jurídicos ${ }^{42}$.

Ahora bien, ese cierto pluralismo jurídico obedece a una pluralidad o diversidad étnica y cultural en el Perú. Como señala PEÑA JUMPA: "Si no existiese pluralidad o diversidad étnica y cultural en el Perú, no hubiere sido necesario ocuparnos de la presente discusión y no habría sido necesario la propia regulación del artículo $149^{\circ}$ de la Constitución Política del Perú"43.

Sin embargo, existen dos valoraciones del concepto de justicia en tanto se apela a diferentes apreciaciones de lo que debe ser la pluralidad. Así, "mientras el Estado juega con una noción de derecho como un bien que él

\footnotetext{
41 Sala Penal Permanente, Recurso de Nulidad No 4382-97 Piura, 09/03/97; Sala Penal Permanente No 4160-96 Huaraz, 07/11/97; Sala Penal Permanente, Exp. N 5622 - 97 Piura, 11/05/98; Sala Penal Transitoria, Exp. No4086-2001 Cajamarca, 03/09/02; Sala Penal Transitoria, Exp. No975-04 San Martín, 09/06/04; Segunda Sala Penal Transitoria, Exp. No 764-2004 Cusco, 16/02/05; Segunda Sala Penal Transitoria, Exp. No $1523-$ 2004 Cusco, 01/03/05; Sala Penal Transitoria, Exp. No 3473-04 Cajamarca, 04/05/05; Sala Penal Transitoria Exp. No 3285-2005 Cajamarca, 16/11/05; Sala Penal Permanente Exp. No 3746-2005 Piura, 07/12/05; Sala Penal Permanente, Exp. No 2174- 2005 Cajamarca, 26/04/06; Sala Penal Transitoria, Exp. № 752-2006 Puno, 17/05/06; Sala Penal Permanente, Exp. No 1836-2006 Amazonas, 04/07/06; Sala Penal Permanente, Exp. No 625-2008 Amazonas, 21/04/08 (Instituto de Defensa Legal - Justicia Viva. «La facultad jurisdiccional de las rondas campesinas. Comentarios al Acuerdo Plenario de la Corte Suprema que reconoce facultades jurisdiccionales a las Rondas Campesinas». Lima 2010, pp. 117- 119).

42 CÁrdenas Krenz, Ronald: «Ejercicio de la función jurisdiccional por las comunidades campesinas y nativas». En: Gaceta Jurídica. La Constitución Comentada. Tomo II. Primera reimpresión, Lima 2006, p. 710.

${ }^{43}$ PeÑa, Antonio. Ob. Cit., p. 130. Asimismo es necesario puntualizar cómo en otras realidades como Colombia y quizás mucho más antes que en Perú se puso en discusión el tema de un derecho paralelo al formal estatal, al que denominan "alternativo", término en el cual se engloba a lo que corresponde a las comunidades indígenas. Así lo hace ver Luís VILLAR BORDA cuando señala: "Mi tesis es, en síntesis, que entre mayor sea el grado de subdesarrollo sea económico, político o cultural) mayor será el grado de ideologización del derecho, tomando éste término en su expresión fuerte, esto es, de encubrimiento de la realidad, de radical diferencia entre las normas, en particular las de carácter constitucional, y los hechos y relaciones que pretenden regular. Por esta razón ha surgido el llamado derecho alternativo, o sea una normatividad paralela a la del estado que rige las relaciones de la sociedad en diferentes ámbitos: las zonas marginadas, los territorios bajo dominio de la guerrilla, los barrios suburbanos y principalmente las comunidades indígenas. Estas últimas con una larga historia anterior al propio descubrimiento de América y que apenas ahora comienzan a ser legalmente reconocidas. Hasta dónde ese derecho alternativo puede integrarse con las normas jurídicas stricto sensu es un debate abierto en toda Latinoamérica" (VILLAR BORDA, Luís. «Derechos Humanos: responsabilidad y multiculturalismo». Universidad Externado de Colombia. Bogotá 1998, p. 97).
} 
mismo otorga o reconoce, los movimientos indígenas y populares, movilizan un modelo ético de la justicia en virtud del cual no sólo demandan el mero reconocimiento de derechos legales, sino también el derecho a vivir una vida digna". Concreta la idea Debora PoOLE señalando: "En el discurso neo-liberal "pluralidad" implica el reconocimiento y tolerancia de diferencias culturales y sociales basadas en identidades heredadas o biológicas). Con respecto al tema de la justicia, sin embargo, este modelo siempre esconde una jerarquía de poder en cuanto que es el Estado el que mantiene el poder de reconocer y subordinar) otros sistemas de justicia, acomodándolos a sus prioridades. En el caso peruano, este proceso de reconocimiento se ha fundamentado hasta el momento en un reconocimiento desigual a formas de vida y comunalidad que implican una valorización distinta del agua, de la tierra y de los recursos naturales" 4445 .

${ }_{44}$ Ejemplificativo del discurso neoliberal es el que toca a Fernando DE TRAZEGNIES quien al caracterizar a la postmodernidad como superación de los problemas de la modernidad señala: "Dado que se trata de una perspectiva que va más allá del sustrato de modernidad de todas las posiciones anteriores, debemos pensar que estamos ante una ruptura. Sin embargo, no debe por ello considerarse que se trata de "otra" tradición: modernidad y postmodernidad forman un continuum, en el que la segunda no sería posible sin la primera. Esta nueva fase organiza los elementos de la tradición occidental de manera nueva, crea otros e incluso ensancha esa tradición mediante la inserción de otras tradiciones antes separadas: en este sentido, la problemática y las antiguas culturas de los países del Tercer Mundo tendrán dentro de la postmodernidad el lugar que les había sido negado por la actitud colonizadora de la modernidad. Pero, a pesar de todos los afluentes que se incorporan al río desde regiones remotas, continúa siendo el río de la tradición occidental que tiene su origen en la concepción griega del hombre y del mundo. No es entonces una tradición diferente sino una explosión dentro de la tradición occidental" (DE TRAZEGNIES, Fernando. "El derecho civil ante la post-modernidad». En: Derecho $N^{\circ}$ 45. Facultad de Derecho/Pontificia Universidad Católica del Perú. Lima, diciembre 1991, p. 317). Igualmente SOBREVILLA: “¿Qué es lo que debemos hacer? ¿Volver a nuestras raíces originarias y cerrarnos a la cultura occidental por haber sido opresiva? ¿Renunciar a las culturas subalternas y desarrollarnos sólo en el sentido de tratar de seguir nuestro proceso de incorporación a la cultura occidental? En nuestra opinión ninguna de estas dos opciones extremas es la correcta sino que debemos seguir asumiendo la cultura occidental, pero de una manera crítica y creadora. En verdad, no podemos renunciar a la cultura occidental y a la modernidad que nos trae porque dicha cultura ha probado a través de sus realizaciones que sus soluciones a muchos problemas de la especie humana han sido sino superiores en todo caso más eficientes que las de otras culturas. Pero tampoco podemos renunciar a nuestras culturas originarias y a seguir impulsándolas, porque son parte de nosotros mismos, por lo que si renunciáramos a ellas nos condenaríamos a ser malas copias. Por otra parte, muchos aspectos de la cultura occidental son problemáticos o están directamente en crisis, de modo que al permanecer atenidos a nuestras otras fuentes culturales podríamos tener una perspectiva distinta para resolver los problemas que ha tratado de solucionar de una manera cuestionable la cultura occidental (...)" (SOBREVILLA ALCAZAR, David: «Globalización, modernidad y multiculturalismo». En: GARCÍA ZÁRATE, Óscar Augusto (Editor). Actas del VIII Congreso Nacional de Filosofía. Filosofía, Globalización y Multiculturalidad. Volumen I. Universidad Nacional Mayor de San Marcos, Facultad de de Letras y Ciencias humanas, Lima 2001, p.139).

45 Resulta sugerente lo planteado por FERRAJOLI en cuanto a bosquejar cuatro posibles modelos de configuración jurídica de las diferencias, partiendo de distinguir a éstas últimas con las desigualdades. Así señala que las primeras tienen que ver con las identidades de las personas (lengua, etnia, religión, opiniones políticas, y la diferencia de sexo, a su parecer la de carácter originario e insuperable que la hace "la diferencia") y las desigualdades tienen que ver con las discriminaciones y disparidades de condiciones sociales. Ferrajoli establece entonces cuatro modelos: 1)de la indiferencia jurídica de las diferencias 2)de la diferenciación jurídica de las diferencias 3)de la homologación jurídica de las diferencias 4)de la igual valoración jurídica de las diferencias. Finalmente, FERRAJOLI señala que este cuarto modelo es el que explica los incisos $1^{\circ} \mathrm{y}$ $2^{\circ}$ del artículo 3 de la Constitución italiana explicándolo así: "La igualdad en los derechos fundamentales 
Entonces con la anterior perspectiva y, en atención a que una visión de la justicia debe estar integrada en un proceso mayor de redistribución del poder, toca preguntarnos, cuál es la función de la judicatura en tanto propugnar la justicia intercultural y, consecuentemente, una justicia inclusiva ${ }^{46}$.

La función asumida por la judicatura apunta a tomar partido por un concepto de justicia intercultural que implique un proceso y una meta. Como proceso se erige el diálogo y la coordinación entre la judicatura ordinaria y la comunal, que conlleva una igualdad entre ambas, resaltando una interculturalidad dinámica de retroalimentación entre culturas ${ }^{47}$. Asimismo, propender la justicia intercultural para todas las personas y grupos y no sólo para los indígenas ${ }^{48}$. Y como meta, la judicatura apunta a contribuir desde el Estado

resulta así configurada como el igual derecho de todos a la afirmación y a la tutela de la propia identidad, en virtud del igual valor asociado a todas las diferencias que hacen de cada persona un individuo diverso de todos los otros y de cada individuo una persona como todas las demás. Pero este igual derecho es, precisamente, una norma, destinada como todas las normas a ser violada en algún grado o medida. De ello se sigue que las diferentes identidades pueden ser reconocidas y valorizadas en la misma medida en que, partiendo no de la proclamación de su abstracta igualdad, sino del hecho de que pesan en las relaciones sociales como factores de desigualdad en violación de la norma sobre la igualdad, se piensen y elaboren no sólo las formulaciones normativas de los derechos sino también sus garantías de efectividad". FERRAJOLI, Luigi. «Derechos y garantías. La ley del más débil». Editorial Trotta, Séptima edición, Madrid 2010, pp.73-76).

46 Como señala Rosembert ARIZA SANTAMARÍA: "El hecho que no es centro de interés legislativo ni jurisprudencial es cómo lograr un ejercicio democrático de la justicia formal, mucho menos de la justicia informal, por ello se presenta a continuación una propuesta que permita el reconocimiento y aprendizaje de parte del derecho positivo respecto al acumulado del derecho profano como un derecho con contenido social y un elevado nivel democrático respecto al derecho formal (...)". Dentro de la propuesta señalado por el autor citado, plantea un aspecto central: "El punto de partida es lo colectivo, no lo general: recuperar el valor de lo comunitario como base de la convivencia social permite un mayor grado de participación en la justicia como un asunto público y de todos y todas". (ARIZA SANTAMARíA, Rosembert. "El derecho profano. Justicia Indígena, justicia informal y otras maneras de realizar lo justo». Universidad Externado de Colombia. Primera edición, octubre 2010, pp. 300,301.

47 ARDITO señala: "A nivel de formalidad, a los funcionarios estatales les corresponde aceptar cierta flexibilidad y a los mecanismos comunitarios introducir niveles mínimos de formalidad que puedan permitir una mejor coordinación a los involucrados con la institucionalidad estatal. El diálogo entre las diversas instituciones podría redundar en mejorar la seguridad jurídica de la población" (ARDITO VEGA, Wilfredo. «La promoción del acceso a la justicia en las zonas rurales. Poder Judicial». Lima, octubre 2011, p. 226. Asimismo, de particular importancia resulta lo dicho por Peña Jumpa: "El problema mayor que se presenta en la coordinación de jueces de paz y magistrados profesionales con las autoridades comunales es respecto a casos complejos que ponen en discusión, de un lado, el ámbito territorial de la jurisdicción de las Comunidades Andinas y Amazónicas y, de otro lado, la transgresión de Derechos Fundamentales bajo percepciones o concepciones culturales diferentes. En términos sencillos se tratarían de casos bajo conflicto de competencia de ambos sistemas de resolución. ¿Quién debía resolver este conflicto de competencias? Tratándose de dos jurisdicciones constitucionales, es la coordinación de ambas bajo un diálogo intercultural el mejor medio de resolución" (PEÑA JUMPA, Antonio. «La jurisdicción especial de las comunidades campesinas y nativas en la Constitución Política del Perú». En: Libro Homenaje al Profesor José Hurtado Pozo. El Penalista de Dos Mundos. IDEMSA, Lima 2013, pp. 937-938).

48 Dibos señala: "(...) hay un abismo entre los discursos y enfoques cercanos a la versión más comprehensiva de interculturalidad, por un lado, y la práctica real del Estado (y de la sociedad en su conjunto) por otro. Es decir, los objetivos de un proyecto ético y político basado en un enfoque más comprensivo de interculturalidad requiere o implica que las políticas interculturales trasciendan el sector educación y se conviertan en relevantes y centrales para todos los sectores del Estado así como para todas las personas y 
a finalizar con ese discurso de la dominación que tiene como principal aspecto, concebir que en una sociedad hay solo una cultura dominante y otras subordinadas per se, lo cual no es aceptable; por el contrario, la convivencia creativa de culturas es una meta o utopía que la judicatura debe contribuir desde su perspectiva, cumpliendo lo que ARGUEDAS planteó para nuestro país como un país de "todas las sangres" 4950.

grupos en el país (no sólo indígenas)”DiBós GÁLVEZ, Alexandra. «¿Entre el ser y la nada? Interculturalidad en la política pública peruana»; p.10).

49 Particularmente interesante resulta lo dicho por CARBONELL en tanto expresa que: "Quizá la misión principal que tienen frente a sí las sociedades democráticas en las que conviven diversas naciones y nacionalidades sigue siendo la muy básica de lograr una cierta homogeneidad social, entendiendo por ella no la posibilidad de arrasar con todas las diferencias, sino el establecimiento de un orden social que permita a todos los miembros de la comunidad el gozo de los derechos vinculados con la satisfacción de sus bienes básicos (...) A partir del aseguramiento de esos bienes básicos se pueden explorar algunas modalidades de los derechos culturalmente diferenciados como las que ya se han mencionado más arriba" (CARBONELL, Miguel. «Problemas constitucionales del multiculturalismo». Fundap, Primera edición, Santiago de Querétaro 2002, pp. 81-82).

50 La exigencia de reconocer la diversidad cultural. Así: "La ausencia del Estado no sólo es material sino política en muchos espacios de la vida peruana. No existe una política lingüística ni cultural de alcance nacional que abarque lo educativo y lo judicial. Esta ausencia, ciertamente, puede llevar a los reformadores judiciales a convertirse en irresponsables lazarillos de un ciego que lo es porque ni siquiera quiere abrir los ojos para mirarse a sí mismo. Es cierto que la tarea no es fácil y que la solución puede ser compleja, pero la marginación y la indiferencia ya sabemos que son las peores vías". (BERNALES BALLESTEROS, Enrique y Antonio RUíz BALLÓN. «La pluralidad cultural en la Constitución peruana de 1993». En.: «Derecho penal y pluralidad cultural. Anuario de Derecho Penal 2006». José HuRTADo POZO (Director). Fondo Editorial de la Pontificia Universidad Católica del Perú - Universidad de Friburgo. Suiza, Lima 2007, p. 39). 